\title{
ORIGEM E AVALIAÇÃO DE TRIGO 'TAPAJÓS' (IAC 72), 'ANHUMAS' (IAC 227) E 'YACO' (IAC 287) PARA O ESTADO DE SÃO PAULO $\left({ }^{1}\right)$
}

\author{
JOÃO CARLOS FELÍCIO $\left({ }^{2}\right)$, CARLOS EDUARDO DE OLIVEIRA CAMARGO $\left({ }^{2.5}\right)$, \\ POLICARPO VITTI $\left({ }^{3,5}\right)$ e JOSÉ CARLOS VILA NOVA ALVES PEREIRA $\left({ }^{4}\right)$
}

\begin{abstract}
RESUMO
Estudou-se o comportamento de trigo 'Tapajós' (IAC 72), 'Anhumas' (IAC 227) e 'Yaco' (IAC 287) quanto à produtividade, às reações aos agentes causais das ferrugens-do-colmo e da-folha (em condição de campo e de casa de vegetação) e à helmintosporiose, em experimentos instalados em solos corrigidos e năo corrigidos em relação à acidez, em condição de sequeiro e de irrigação por aspersão, em diferentes regiões paulistas, no período de 1987-91. Os cultivares foram submetidos a testes para avaliação de tolerância a ferro, alumínio e manganês, empregando-se soluções nutritivas, em laboratório. Avaliaram-se também as qualidades físicas e reológicas das farinhas obtidas dos grãos desses cultivares e efetuou-se o teste final de panificação. Nas condições de sequeiro, os cultivares IAC 227 e IAC 72 foram mais produtivos em 20 e $5 \%$, respectivamente, em relação ao $\mathrm{BH} 1146$, tomado como controle. O IAC 287 , nas mesmas condiçōes de cultivo, apresentou uma produção de grãos $10 \%$ maior em relação à testemunha, Anahuac, e em condição de irrigação foi superior em 7 e $6 \%$ aos controles Anahuac e IAC 24 respectivamente. Para a ferrugem-do-colmo, em casa de vegetação, o IAC 72 demonstrou suscetibilidade às raças G20 e G21; o IAC 227, às raças G11, G15 e G17; o BH 1146 mostrou-se sensível e os cultivares IAC 287 e Anahuac, resistentes a todas as raças testadas. Os testes para reação a Puccinia recondita, em casa de vegetação, demonstraram
\end{abstract}

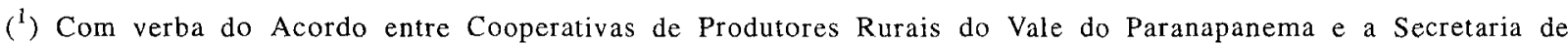
Agricultura e Abastecimento, por intermédio do Instituto Agronômico. Recebido para publicação em 27 de abril de 1992 e aceito em 6 de julho de 1994.

$\left(^{2}\right)$ Seção de Arroz e Cereais de Inverno, Instituto Agronômico (IAC), Caixa Postal 28, 13001-970 Campinas (SP).

$\left({ }^{3}\right)$ Seção de Cereais, Farinha e Panificação, Instituto de Tecnologia de Alimentos (ITAL), Caixa Postal 139, 13001-970 Campinas (SP).

( $\left.{ }^{4}\right)$ Estação Experimental de Ribeirão Preto, IAC.

( ${ }^{5}$ ) Com bolsa de pesquisa do CNPq. 
suscetibilidade dos cultivares IAC 72, IAC 227, BH 1146 e Anahuac, enquanto o IAC 287 mostrou-se resistente. Esses resultados foram confirmados nos testes de campo. Todos os cultivares em estudo apresentaram-se sensíveis à ocorrência do agente causal da helmintosporiose. O IAC 72 revelou moderada suscetibilidade ao $\mathrm{Al}^{3+}$ e $\mathrm{Mn}^{2+}$ e sensibilidade ao $\mathrm{Fe}^{2+}$; o IAC 227 foi tolerante a altas doses de $\mathrm{Al}^{3+}$ e a $\mathrm{Mn}^{2+}$ e sensível ao $\mathrm{Fe}^{2+}$; o IAC 287 , tolerante ao $\mathrm{Fe}^{2+}$ e $\mathrm{Mn}^{2+}$ e sensível ao $\mathrm{Al}^{3+}$. Nos testes de panificação, os volumes específicos comparativos dos cultivares IAC 287 e IAC 227 foram 5,64 e 3,76\% superiores ao do padrão (grão comercial) respectivamente, e o IAC 72 foi inferior a este. Na avaliação final comparativa, somente o IAC 287 igualou-se ao padrão (100\%).

Termos de indexação: trigo, produtividade, resistência a doenças, tolerância a $\mathrm{Fe}^{2+}$, $\mathrm{Mn}^{2+}$ e $\mathrm{Al}^{3+}$, características de panificação.

\section{ABSTRACT \\ EVALUATION OF THE AGRONOMIC AND TECHNOLOGIC CHARACTERISTICS OF THE WHEAT CULTIVARS: IAC 72 TAPAJÓS, IAC 227 ANHUMAS AND IAC 287 YACO IN THE STATE OF SÃO PAULO, BRAZIL}

The wheat cultivars IAC 72 Tapajós, IAC 227 Anhumas and IAC 287 Yaco were evaluated in relation to grain yield, response to infection by leaf and stem rusts (under field and greenhouse conditions) and leaf spots, in experiments carried out in limed and acid soils, in upland and under sprinkler irrigation. All these evaluations were performed in different regions of the State of São Paulo, Brazil, from 1987 to 1991 . The cultivars were also studied for tolerance to iron, aluminium and manganese toxicities, using nutrient solutions, in the laboratory. Assays for physical, rheological and bread quality were made with the flours of each cultivar. In upland conditions, the results showed that IAC 227 produced $20 \%$ and IAC 72 , $5 \%$ more than $\mathrm{BH} 1146$, used as control. Under the same condition, cultivar IAC 287 showed a grain yield of $10 \%$ greater than the control Anahuac. However, under sprinkler irrigation, IAC 287 showed an increase in grain yield of 7 and $6 \%$ as compared to the control cultivars Anahuac and IAC 24, respectively. Under greenhouse conditions, the cultivar IAC 72 was susceptible to races $G 20$ and $G 21$ of the causal agent of stem rust. The cultivar IAC 227 showed susceptibility to races G11, G15 and G17 of stem rust. BH 1146 was sensitive while IAC 287 and Anahuac were resistant to all tested races. Concerning to the reactions to races of Puccinia recondita, the cultivars IAC 72, IAC 227, BH 1146 and Anahuac were susceptible and IAC 287 behaved as resistant under greenhouse conditions. These results were confirmed under field conditions. All studied cultivars were susceptible to the causal agent of leaf spots. IAC 72 presented as moderately sensitive to $\mathrm{Al}^{3+}$ and $\mathrm{Mn}^{2+}$ and sensitive to $\mathrm{Fe}^{2+}$, and IAC 287 was tolerant to $\mathrm{Fe}^{2+}$, and $\mathrm{Mn}^{2+}$, but sensitive to $\mathrm{Al}^{3+}$ showing toxicity signs. Considering the trials on bread characteristics, the cultivars IAC 287 and IAC 227 showed superiority in specific volume of 5.64 and $3.76 \%$ in relation to the breads made with commercial flour, respectively. The cultivar IAC 72 did not present a good performance for breads in relation to the control. At the final evaluation, only the cultivar IAC 287 was as good as the control.

Index terms: wheat, grain yield, disease resistance, tolerance to $\mathrm{Al}^{3+}, \mathrm{Fe}^{2+}$ and $\mathrm{Mn}^{2+}$, bread characteristcs. 


\section{INTRODUÇÃo}

Segundo Cuyabano (1964), a cultura do trigo no Estado de São Paulo data de 1556, quando foi introduzida na Capitania de São Vicente. Daí deslocou-se para os campos de Piratininga, onde se estabeleceu, dando origem aos primeiros moinhos. Com o aparecimento da ferrugem do colmo (Puccinia graminis Pers. forma sp. tritici Eriks, et E. Henn.), houve decadência da cultura, que passou para o Sul do País.

De modo geral, os cultivares brasileiros de trigo têm porte alto (Osório, 1982), especialmente os cultivados ao sul do paralelo $24^{\circ} \mathrm{S}$. Os solos da região Sul do Brasil são, em geral, de baixa fertilidade, alcançando o trigo menor desenvolvimento. Normalmente, portanto, não ocorre acamamento, mesmo quando utilizados cultivares de alta estatura. $\mathrm{Na}$ região ao norte do paralelo $24^{\circ} \mathrm{S}$, os cultivares de porte alto sofrem intenso acamamento quando cultivados em solos de boa fertilidade, não sendo, portanto, recomendados em tais condições.

Grandes áreas do território brasileiro têm solos ácidos, contendo alumínio livre, o qual inibe o crescimento das raízes da maior parte dos cultivares de trigo, trazendo como conseqüência pouco perfilhamento e baixos rendimentos (Hanson et al., 1982).

De acordo com Mundstoch (1983), a escolha correta das variedades a utilizar em uma lavoura é de fundamental importância na obtenção de bons resultados. Para atingir altos rendimentos, é imperioso que existam variedades adaptadas às condições de cultivo e edafoclimáticas, o que só é possível com o desenvolvimento de programas de melhoramento genético em âmbito estadual e regional. Há que considerar, ainda, que distintas classes e tipos de trigo são utilizados para diferentes propósitos. As variedades de trigo duro (hard) são os trigos para pão. Apresentam um glúten forte (a farinha é granular), que, quando se transforma em massa, absorve grandes quantidades de água, produzindo bom volume específico e boa consistência.

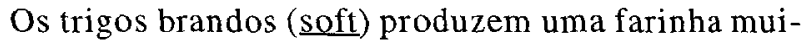
to fina, mais apropriada para a utilização em massas de pastéis e bolachas, sendo demasiado fraca para a fabricação de pães. O Triticum durum L. é impróprio para os usos citados, sendo específico para a fabricação de pastas. Essas diversas utilizações das distintas classes de trigo comercial refletem as características físicas e químicas inerentes a cada classe de trigo (Poehlman, 1974).

Nos anos recentes, as variedades mais cultivadas no Estado de São Paulo têm sido: Anahuac, IAC 24, BH 1146, IAC 18 e IAC 5 (Silva et al., 1989). Tais variedades, entretanto, têm sido indicadas pela pesquisa agronômica basicamente em função da produtividade agrícola, sem qualquer esforço, até o presente, com vistas a uma recomendação para finalidades específicas, como ocorre em outros países.

É evidente, em face de tantos aspectos a considerar, que trabalho de melhoramento genético, com vistas à criação de novas variedades de trigo, é demorado. Inicialmente, cabe investigar as melhores variedades diante das diferentes exigências locais de cultivo, como época de plantio, resistência às moléstias e pragas, produtividade, qualidades industriais do grão para moinho, a panificação e outros usos. Exige conhecimento especializado para a distinção das variedades em estudo e eleição das que devem ser cruzadas para possibilitar obtenção de novos genótipos adequados às condições locais (Teixeira, 1958).

Mediante trabalhos de melhoramento genético, foram selecionados novos cultivares de trigo no Instituto Agronômico de Campinas (Felício et al., $1983,1985,1988$ e 1990b), adaptados às condições de clima e solo da região tritícola situada ao norte do pararelo $24^{\circ} \mathrm{S}$. Em tais condições, destacam-se os cultivares IAC 18 (Xavantes), IAC 21 (Iguaçu) e IAC 24 (Tucuruí), este, de porte semi-anão e com tolerância ao alumínio tóxico, e, mais recentemente, os cultivares IAC 25 (Pedrinhas) e IAC 161 (Taiamã).

Neste trabalho, são relatadas a origem e as características agronômicas e tecnológicas, o desempenho em diferentes condiçōes de cultivo e edafoclimáticas, de três outros novos cultivares, quais sejam: IAC 72 (Tapajós), IAC 227 (Anhumas) e IAC 287 (Yaco). 


\section{MATERIAL E MÉTODOS}

O cultivar IAC 72 (Tapajós) foi obtido pelo método genealógico de seleção (Allard, 1960), provindo do híbrido $\mathrm{CB} 75$, originário do cruzamento Tobari 66/IAC 5. A primeira é originária do Centro Internacional de Melhoramento de Milho e Trigo (CIMMYT) - México, proveniente do cruzamento Tezanos Pinto Precoce/Sonora 64A III90214M-3Y-102M-100Y-101C; o cultivar IAC 5 Maringá é resultante do cruzamento Fontana/Kenya 58//Ponta Grossa I (Camargo, 1972). O 'Tapajós' apresenta as seguintes características: altura entre 100 e $110 \mathrm{~cm}$; ciclo médio de 125-130 dias da emergência à colheita; aurícula verde-amarelado-clara; folha intermediária, verde-clara, e espiga de coloração creme, aristada, oblonga, densa, com comprimento de $9,0 \mathrm{~cm}$, e grão ovóide de coloração creme (Figura 1).

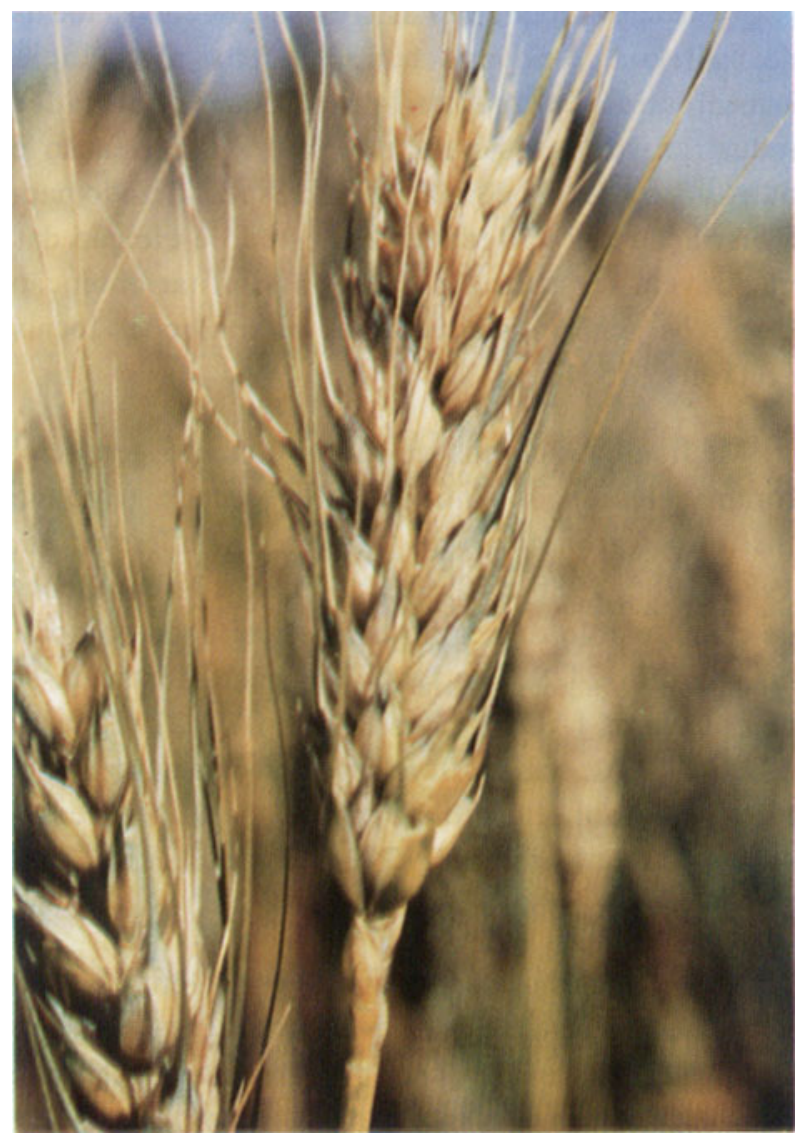

Figura 1. Espigas características do cultivar IAC 72 Tapajós, em fase de granação.
O cultivar IAC 227 (Anhumas) também foi obtido pelo método genealógico, originário de seleção do híbrido CNT 9/BH 1146. O primeiro é oriundo do cruzamento Curitiba/Pioneiro//Curitiba/ Tokai66 (PEL 72016), do Centro Nacional de Pesquisa do Trigo, Passo Fundo (RS), e o 'BH 1146' é resultante do cruzamento Ponta Grossa 1/Fronteira//Mentana, do Instituto Agronômico de Minas Gerais (MG). O 'Anhumas' apresenta as seguintes características: altura de $90-100 \mathrm{~cm}$; ciclo precoce, de 115-120 dias da emergência à colheita; aurícula verde-amarelado-clara; folha pendente verde-clara e espiga de coloração creme aristada, fusiforme, densa, com comprimento aproximado de $8,5 \mathrm{~cm}$; grãos elípticos e de coloração creme (Figura 2).

O cultivar IAC 287 (Yaco) é uma linhagem selecionada no Instituto Agronômico de Campinas (SP), proveniente do híbrido Heima/Cocoraque// /Nacozare 76, introduzido e resselecionado do CIMMYT. O cultivar Yaco apresenta as seguintes características: altura de plantas de $80-90 \mathrm{~cm}$; ciclo precoce, de 115-120 dias da emergência à maturação; hábito vegetativo ereto; aurícula com presença de antocianina (violácea); folha de posição intermediária, de cor verde (intermediária); espiga creme, aristada e fusiforme, semidensa, com comprimento aproximado de $10,5 \mathrm{~cm}$; grão creme (Figura 3).

Foram extraídos os dados referentes ao período 1987-91 dos cultivares IAC 72 (Tapajós) e IAC 227 (Anhumas), estudados em condições de sequeiro, em ensaios instalados em blocos ao acaso, com quatro repetições em solos não corrigidos com relação à acidez, nos municípios paulistas de Cândido Mota, Maracaí, Capão Bonito e Paranapanema. Nesses ensaios, utilizou-se como controle o cultivar BH 1146, que apresenta boa produtividade em solos dessa natureza e contém alumínio tóxico. Em todos os experimentos, cada parcela foi constituída de seis linhas de $3 \mathrm{~m}$ de comprimento, espaçadas de $0,20 \mathrm{~cm}$, reservando-se $0,6 \mathrm{~m}$ entre as parcelas.

Os dados de produção e as notas referentes a doenças foram submetidas à analise estatística segundo o modelo para grupos de experimentos, de acordo com Pimentel Gomes (1970). 
O 'IAC 287' (Yaco) também foi avaliado em condições de sequeiro no período de 1988-91, em solos corrigidos ou com boa fertilidade natural, no Vale do Paranapanema, nos municípios de Maracaí, São José das Laranjeiras e Cruzália. Esse cultivar foi ainda avaliado em condições de irrigação por aspersão, em 1988-91, nos municípios de Colômbia, Guaíra, Jaborandi e Mococa, sendo, neste último, os ensaios desenvolvidos em solos que já tinham recebido calagem. Nesses ensaios, estudados em blocos ao acaso com quatro repetições, utilizaram-se os cultivares Anahuac e IAC-24 como controles, tendo em vista sua adaptabilidade às condições edafoclimáticas e de cultivo correspondentes.

As análises de amostras compostas dos solos dos locais onde se instalaram os experimentos foram efetuadas pela Seção de Fertilidade do Solo e Nutrição de Plantas do IAC e os experimentos receberam adubação a lanço, constante de $20 \mathrm{~kg}$ de $\mathrm{N}, 60$

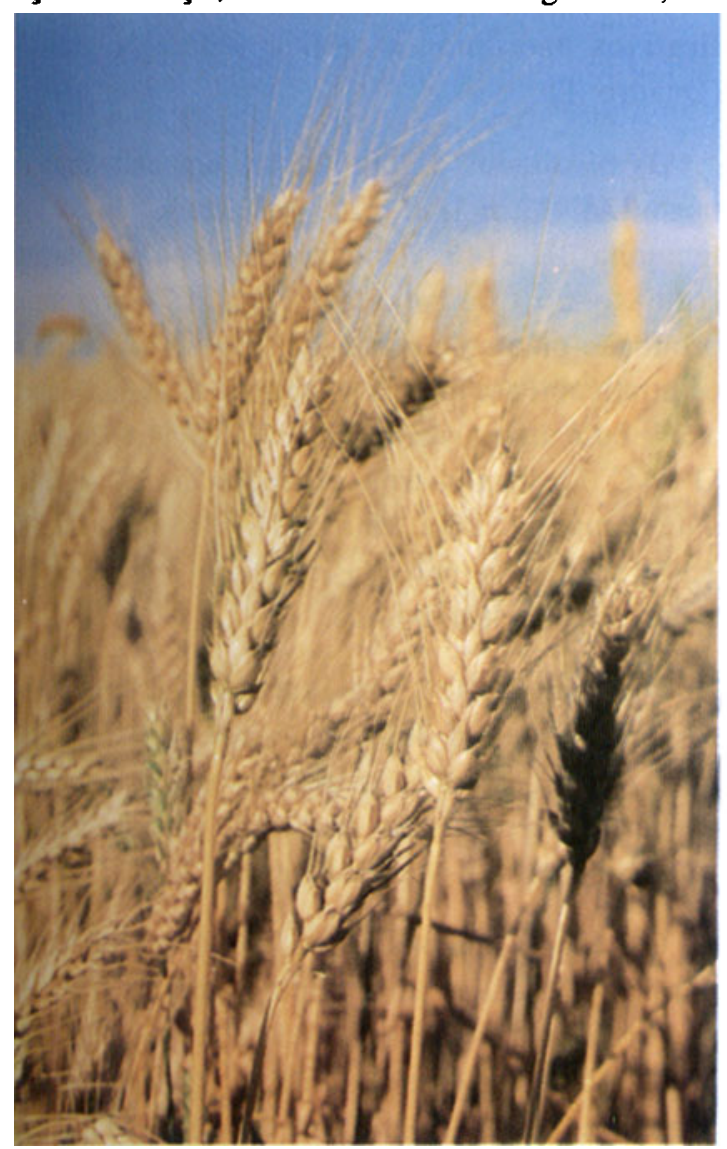

Figura 2. Espigas características do cultivar IAC 227 Anhumas, em fase de maturação. $\mathrm{kg}$ de $\mathrm{P}_{2} \mathrm{O}_{5}$ e $20 \mathrm{~kg}$ de $\mathrm{K}_{2} \mathrm{O}$ por hectare, nas formas de sulfato de amônio, superfosfato simples e cloreto de potássio respectivamente.

Para o estudo do comportamento dos cultivares em relação à ferrugem-do-colmo (Puccinia grami$n i s$ f. sp. tritici) e à ferrugem-da-folha ( $P$. recondita f. sp. tritici), avaliaram-se plântulas, no Centro Nacional de Pesquisa de Trigo, de acordo com os critérios apresentados nos quadros 5 e 6 . Utilizaram-se os cultivares BH 1146 e Anahuac como controle nos testes de reação a essas doenças em casa de vegetação. Para a leitura das doenças em condição de campo, adotou-se a escala modificada de Cobb, empregada no "International Rust Nursery" e utilizada por Schramm et al. (1974), a qual é composta por um número estimado em porcentagem de ataque de moléstia no colmo e na folha. Para a helmintosporiose (Helminthosporium sp.) ocorrente nas folhas, as informações foram estimadas em porcentagem de área foliar infectada.

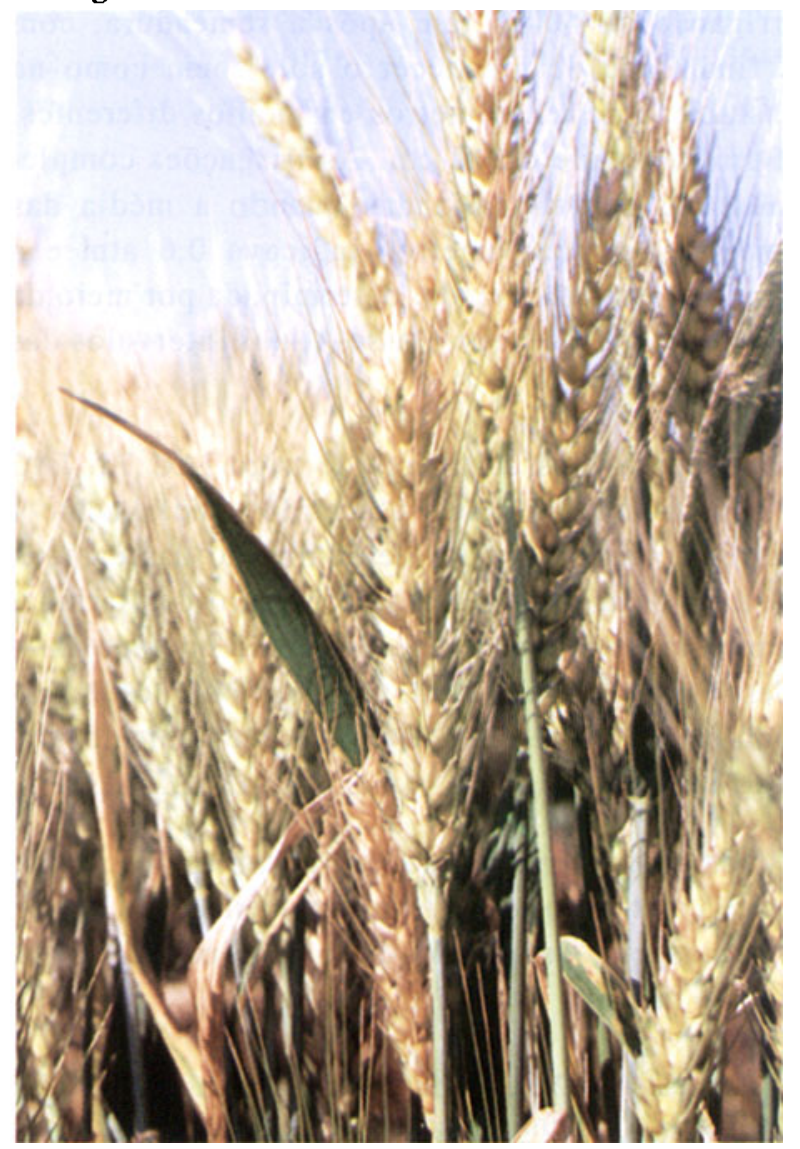

Figura 3. Espigas características do cultivar IAC 287 Yaco, em fase de granação. 
A altura de cada cultivar foi medida, levando-se em consideração a distância do nível do solo ao ápice da espiga, mantendo-se as plantas esticadas, excluindo as aristas.

Os cultivares IAC 72, IAC 227 e IAC 287 foram testados para a tolerância a $0,2,4,6,8$ e $10 \mathrm{mg}$ de $\mathrm{Al}^{3+} /$ litro, mantendo-se constante a temperatura de $25^{\circ} \mathrm{C}$ (Camargo et al., 1987); para a tolerância a $0,11,300,600$ e $1.200 \mathrm{mg}$ de $\mathrm{Mn}^{2+} /$ litro (Camargo \& Oliveira, 1983), e para a tolerância a $0,56,5$, 10 e $20 \mathrm{mg}$ de $\mathrm{Fe}^{2+} /$ litro (Camargo et al., 1988), empregando-se soluções nutritivas. Em todos os testes, utilizaram-se como controle os cultivares $\mathrm{BH}$ 1146 - tolerante à toxicidade de $\mathrm{Al}^{3+}$ e sensível à toxicidade de $\mathrm{Mn}^{2+}$ e $\mathrm{Fe}^{2+}$, e Siete Cerros - sensível à toxicidade de $\mathrm{Al}^{3+}$ e tolerante à de $\mathrm{Mn}^{2+}$ e $\mathrm{Fe}^{2+}$.

Nos ensaios irrigados, adotou-se o método proposto por Silva et al. (1984): consiste em uma irrigação de 40-60 $\mathrm{mm}$ após a semeadura, com a finalidade de umedecer o solo, bem como na instalação de tensiômetros em pontos diferentes, à profundidade de $12 \mathrm{~cm}$. As irrigações complementares foram realizadas quando a média das leituras dos tensiômetros indicava $0,6 \mathrm{~atm}$ e a lâmina líquida aplicada, determinada por meio da evaporação no tanque classe $\mathrm{A}$, nos intervalos das irrigações.

Os grãos dos cultivares de trigo IAC 72 , IAC 227 e IAC 287 foram submetidos inicialmente a testes de moagem para determinação das características de maturamento e de preparo das farinhas para análises posteriores. O método adotado foi o descrito por Felício et al. (1985). Como teste comparativo, usou-se grão de trigo proveniente de moinho comercial.

Os grãos foram acertados na umidade de acordo com o método oficial (Arbeitsgemeinschalt, 1971). $\mathrm{Na}$ moagem, determinou-se o rendimento em farinha, farelo e farelo fino.

A farinha obtida na moagem foi submetida à análise de ordem física no farinógrafo, no amilógrafo e no extensógrafo, segundo método oficial da AACC (1969). O teor de glúten e o de "falling number" foram determinados pelo método oficial (Arbeitsgemeinschalt, 1971).

Nos testes de panificação, utilizou-se o processo descrito por Vitti et al. (1982). Compararam-se os pães preparados com as farinhas dos cultivares em estudo, com aqueles provenientes da farinha da amostra comercial. Tanto no preparo dos pães tipo francês como na sua avaliação, adotou-se também o método de Vitti et al. (1982).

\section{RESULTADOS E DISCUSSÃO}

Os quadrados médios da análise conjunta da variância (I) para a produção de grãos de trigo dos experimentos estudados em solos não corrigidos em condição de sequeiro, nas localidades de Cândido Mota, Maracaî, Capão Bonito e Paranapanema, mostraram efeitos significativos para ano, local e cultivar e para a interação ano x local, e não significativos para ano $x$ cultivar e local $x$ cultivar (Quadro 1).

Os resultados das produções dos cultivares de trigo IAC 72 e IAC 227, comparados ao da testemunha BH 1146, estudados nesses locais, encontram-se no quadro 2. O IAC 227 apresentou produção média de grãos de $2.216 \mathrm{~kg} / \mathrm{ha}$, diferindo estatisticamente do BH 1146 pelo teste de Dunnett a $5 \%$, com uma superioridade de $20 \%$ (1.852 kg/ha). O IAC 72 demonstrou produção de $5 \%$ superior à testemunha, com uma produtividade média de $1.950 \mathrm{~kg} / \mathrm{ha}$ no período, mas não diferiu estatisticamente da testemunha.

O cultivar IAC 287 foi estudado em experimentos instalados em duas condições: sequeiro e irrigado por aspersão. Os quadrados médios da análise da variância para dois grupos de experimentos (II e III) encontram-se no quadro 1.

Os dados demonstraram efeitos significativos para ano, local e para a interação ano $\mathrm{x}$ local, e não significativo para cultivar e para as interações local $x$ cultivar e ano $x$ cultivar nas condições de sequeiro (Maracaí, São José das Laranjeiras e Cruzália). Para os experimentos com irrigação, a análise da variância apresentou o mesmo resultado. 
Conforme se verifica no quadro 3, o cultivar IAC 287 apresentou, em condições de sequeiro, produção de grãos de $1.860 \mathrm{~kg} / \mathrm{ha}$ comparado a $1.696 \mathrm{~kg} / \mathrm{ha}$ do 'Anahuac', representando um aumento de $10 \%$ na produção por unidade de área. Em áreas irrigadas por aspersão (Quadro 4), o IAC 287 foi superior em 7 e $6 \%$, respectivamente, às testemunhas Anahuac e IAC 24; em ambos os casos, não houve diferença estatística significativamente entre os cultivares estudados, apesar do aumento na produtividade de grãos.
A interação ano x local foi significativa nos três grupos de experimentos, comprovando estudos anteriores de Felicio et al. (1990a e 1993). Já a interação local x cultivar não foi significativa, possivelmente devido à boa adaptação regional dos cultivares. É provavel que efeitos microclimáticos associados à maior ou à menor acidez do solo tenham influenciado a produtividade, mesmo em solos corrigidos, pois ocorreram diferenças altamente significativas entre as localidades.

Quadro 1. Quadrados médios da análise da variância conjunta para rendimento de grãos de cultivares de trigo avaliados I: em condição de sequeiro, nas localidades de Cândido Mota, Maracaí, Capão Bonito e Paranapanema; II: em condição de sequeiro, em Maracaí, São José das Laranjeiras e Cruzália, e III: em condição de irrigação, em Colômbia, Guaíra, Jaborandi e Mococa

\begin{tabular}{|c|c|c|c|c|c|c|}
\hline \multirow{2}{*}{ Causas da variação } & \multicolumn{2}{|c|}{ 1987-1991 (I) } & \multicolumn{2}{|c|}{ 1988-1991 (II) } & \multicolumn{2}{|c|}{ 1987-1991 (III) } \\
\hline & G.L. & Q. médio & G.L. & Q. médio & G.L. & Q. médio \\
\hline Ano & 4 & $3.466 .646^{*}$ & 3 & $1.346 .955^{*}$ & 4 & $4.733 .296^{*}$ \\
\hline Local & 3 & $335.155^{*}$ & 2 & $1.226 .017^{*}$ & 3 & $3.691 .554 *$ \\
\hline Cultivar & 2 & $708.739 *$ & 1 & $162.855 \mathrm{~ns}$ & 2 & $328.613 \mathrm{~ns}$ \\
\hline Ano $x$ local & 12 & $638.959 *$ & 6 & $352.454 *$ & 12 & $1.706 .294 *$ \\
\hline Ano $x$ cultivar & 8 & $93.907 \mathrm{~ns}$ & 3 & $53.074 \mathrm{~ns}$ & 8 & $137.568 \mathrm{~ns}$ \\
\hline Local $\mathrm{x}$ cultivar & 6 & $75.628 \mathrm{~ns}$ & 2 & $21.785 \mathrm{~ns}$ & 6 & $225.255 \mathrm{~ns}$ \\
\hline Ano $x$ local $x$ cultivar & 24 & 74.653 & 6 & 56.661 & 24 & 149.129 \\
\hline
\end{tabular}

*: Significativo ao nível de $5 \%$; ns: não significativo.

Quadro 2. Produtividade de grãos dos cultivares de trigo IAC 72, IAC 227 e BH 1146 extraída dos ensaios semeados em condição de sequeiro em solos não corrigidos em diferentes localidades paulistas, no período 1987-1991

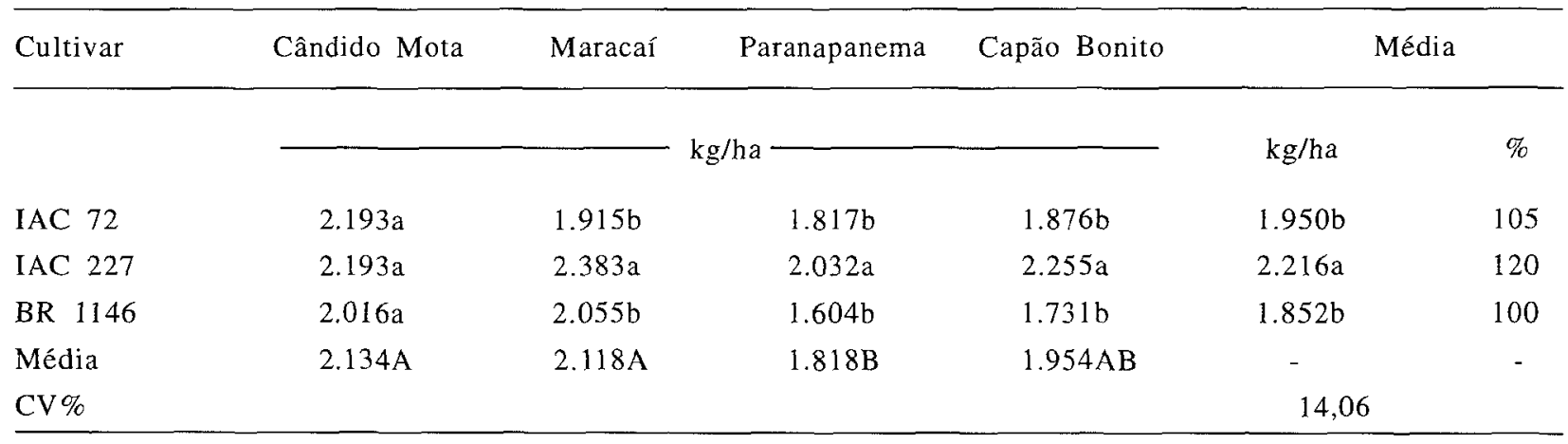

Obs: Comparação da produção de grãos entre cultivares dentro de um local em letras minúsculas pelo teste de Dunnett e médias para comparação entre locais em letras maiúsculas pelo teste de Duncan. Médias seguidas pela mesma letra não diferem estatisticamente entre si a $5 \%$ de probabilidade. 
As avaliações dos novos cultivares quanto à resistência a $P$. graminis f. sp. tritici em casa de vegetação encontram-se no quadro 5 . O cultivar IAC 227 apresentou reação idêntica ao seu genitor $\mathrm{BH}$ 1146, exceto para as raças G11, G15, G17 e G25, e segregação para G18 e G23. O cultivar IAC 72 demonstrou suscetibilidade às raças G20, G21 e G24, e o IAC 287, resistência para todas as raças testadas do agente causal da ferrugem-do-colmo, com reações semelhantes ao Anahuac.

No quadro 6 são demonstradas as reações dos cultivares IAC 72, IAC 227 e IAC 287 às raças testadas de $P$. recondita em casa de vegetação. Os cultivares IAC 72 e IAC 227 apresentaram maior severidade de reação ao agente causal da ferrugem- -da-folha, se comparados ao IAC 287. Entre os controles, o BH 1146 foi mais sensível que o Anahuac.

As reações em campo foram estudadas somente para o agente causal de $P$. recondita devido à baixa ocorrência, nos anos em estudo, de infestação do agente causal da ferrugem-do-colmo. No quadro 7 , encontram-se resultados para os cultivares IAC 72, IAC 227 e BH 1146 e, no quadro 8, para os cultivares IAC 287, Anahuac e IAC 24.

$\mathrm{Na}$ condição de sequeiro em campo, o 'IAC $227^{\prime}$ apresentou menor reação de suscetibilidade ao agente causal da ferrugem-da-folha, comparado ao $\mathrm{BH} 1146$, e este, com notas inferiores ao IAC 72 , que se revelou mais sensível à doença.

Quadro 3. Produções médias de grãos de trigo do cultivar IAC 287, obtidas nos ensaios instalados em condição de sequeiro em diferentes localidades do Estado de São Paulo no período 1988-1991

\begin{tabular}{|c|c|c|c|c|c|}
\hline Cultivar & $\begin{array}{c}\text { São José } \\
\text { das Laranjeiras }\end{array}$ & Cruzália & Maracaí & \multicolumn{2}{|c|}{ Média } \\
\hline & $\ldots$ & $-\mathrm{kg} / \mathrm{ha}-$ & 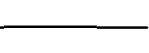 & $\mathrm{kg} / \mathrm{ha}$ & $\%$ \\
\hline IAC 287 & $2.217 \mathrm{a}$ & $1.849 \mathrm{a}$ & $1.515 \mathrm{a}$ & $1.860 \mathrm{a}$ & 110 \\
\hline Anahuac & $2.169 \mathrm{a}$ & $1.602 \mathrm{~b}$ & $1.316 \mathrm{~b}$ & $1.696 \mathrm{~b}$ & 100 \\
\hline Média & $2.193 \mathrm{~A}$ & $1.725 \mathrm{~B}$ & $1.415 \mathrm{C}$ & - & - \\
\hline $\mathrm{CV} \%$ & & & & 13,38 & \\
\hline
\end{tabular}

Obs: Comparaçāo da produção de grãos entre cultivares dentro de um local em letras minúsculas pelo teste de Dunnett e médias para comparação entre locais em letras maiúsculas pelo teste de Duncan. Médias seguidas pela mesma letra não diferem estatisticamente entre si a $5 \%$ de probabilidade.

Quadro 4. Produções médias de grãos de trigo do cultivar IAC 287, obtidas nos ensaios instalados em condição de irrigação por aspersão em diferentes localidades paulistas de 1987 a 1991

\begin{tabular}{|c|c|c|c|c|c|c|c|}
\hline \multirow[t]{2}{*}{ Cultivar } & Guaíra & Colômbia & Mococa & Jaborandi & \multicolumn{3}{|c|}{ Média } \\
\hline & \multicolumn{4}{|c|}{${ } \mathrm{kg} / \mathrm{ha}$} & $\mathrm{kg} / \mathrm{ha}$ & - & - \\
\hline IAC 287 & $4.377 \mathrm{a}$ & $3.615 \mathrm{a}$ & $3.416 \mathrm{a}$ & $3.147 \mathrm{a}$ & $3.639 \mathrm{a}$ & 107 & 106 \\
\hline Anahuac & $4.320 \mathrm{a}$ & $3.496 \mathrm{a}$ & $2.852 b$ & $3.045 \mathrm{a}$ & $3.428 \mathrm{~b}$ & 100 & - \\
\hline IAC 24 & $3.798 \mathrm{~b}$ & $3.354 \mathrm{a}$ & $3.295 \mathrm{a}$ & $2.981 \mathrm{a}$ & $3.407 \mathrm{~b}$ & - & 100 \\
\hline Média & $4.165 \mathrm{~A}$ & $3.555 \mathrm{~B}$ & $3.188 \mathrm{~B}$ & $3.058 \mathrm{C}$ & - & - & - \\
\hline $\mathrm{CV} \%$ & & & & & 11,06 & & \\
\hline
\end{tabular}

Obs: Comparação de produção de grãos entre cultivares dentro de um local em letras minúsculas pelo teste de Dunnett e médias para comparação entre locais em letras maiúsculas pelo teste de Duncan. Médias seguidas pela mesma letra não diferem entre si a $5 \%$ de probabilidade. 
Quadro 5. Reações de cultivares de trigo às raças de Puccinia graminis f. sp. tritici em casa de vegetação, no estádio de plântula

\begin{tabular}{lccccccccccc}
\hline \multirow{2}{*}{ Cultivar } & \multicolumn{10}{c}{ Raças } \\
\cline { 2 - 11 } & G11 & G15 & G17 & G18 & G19 & G20 & G21 & G22 & G23 & G24 & G25 \\
\hline IAC 72 & $0 ;$ & $0 ;$ & $1-$ & 1 & 1 & 3 & 3 & $0 ;$ & $0 ;$ & $2 / 3$ & 0 \\
IAC 287 & $0 ;$ & 0,1 & 0 & 0 & $1+$ & $; 1$ & $; 1-$ & 0 & $; 1$ & $; 1-$ & $; 1$ \\
IAC 227 & 1 & 2 & $0 ;$ & $0 ; 1$ & 3 & 3 & 3 & 3 & $0 ; 1$ & 3 & 2 \\
Anahuac & $1-$ & $2-$ & $0 ;$ & $0 ;$ & 2 & 0 & 1 & $1-$ & $0 ;$ & $0 ;$ & $0 ;$ \\
BH 1146 & 4 & 4 & 4 & 4 & 3 & 4 & 4 & 4 & 4 & 4 & 4 \\
\hline
\end{tabular}

Reações: 0 0; 1 e 2 = resistente, 3 e 4 = suscetível, + - = maior ou menor severidade da reação, ; = segregação ou mistura de sementes. $/$ = avaliações distintas.

Quadro 6. Reações de cultivares de trigo às raças de $P$. recondita f. sp. tritici, em casa de vegetação, no estádio de plântula

\begin{tabular}{lcccccccc}
\hline \multirow{2}{*}{ Cultivar } & \multicolumn{10}{c}{ Raças } \\
\cline { 2 - 9 } & B25 & B26 & B27 & B29 & B30 & B31 & B32 & B33 \\
\hline IAC 72 & 3 & 3 & $0 ;, 2$ & 2 & $0 ; 2$ & $0 ;, 2$ & $3 / 2$ & $0 / 0 ; 3$ \\
IAC 287 & $0 ;$ & $0 ;$ & $;$ & $0 ;$ & 1 & $0 ;$ & 0 & $; 0 ;$ \\
IAC 227 & 3 & 3 & 3 & $0 ;$ & $0 ;$ & 3,2 & 3 & $0 ; / 0 ; 3$ \\
Anahuac & 1 & $0 ; / 2$ & 1 & $0 ; / 0,3$ & 4 & $0 ;$ & $0 ; / 0,3$ & $0 ;$ \\
BH 1146 & 3 & 3,2 & 3 & $0,-3 / 4$ & $3, ; 2$ & 3 & $3 / 3-0 ; 3$ & \\
\hline
\end{tabular}

Reações: 0 0; 1 e 2 = resistente; 3 e 4 = suscetível, + - = maior ou menor severidade da reação, ; = segregação ou mistura de sementes, $/$ = avaliaçōes distintas.

Quadro 7. Reações médias em porcentagem de área foliar infectadas pelo agente causal da ferrugem-da-folha, nos cultivares de trigo IAC 72, IAC 227 e BH 1146 em condições de sequeiro no período 1987-91, nas localidades estudadas

\begin{tabular}{lrrrrrr}
\hline \multirow{2}{*}{ Cultivar } & \multicolumn{5}{c}{ Anos } & Média \\
\cline { 2 - 5 } & 1987 & 1988 & 1989 & 1990 & 1991 & $10,5 \mathrm{a}$ \\
IAC 72 & 15,00 & 10,00 & 12,50 & 12,5 & 2,5 & $4,5 \mathrm{~b}$ \\
IAC 227 & 8,75 & 0,00 & 6,25 & 5,0 & 2,5 & $5,3 \mathrm{ab}$ \\
BH 1146 & 5,00 & 5,00 & 8,75 & 7,5 & 0,0 & $1,88 \mathrm{~ns}$ \\
Média & $9,58 \mathrm{~A}$ & $9,16 \mathrm{~A}$ & $8,33 \mathrm{~A}$ & $5,0 \mathrm{~A}$ & $1,7 \mathrm{~A}$ & $2,97 \mathrm{~ns}$ \\
F. (Ano) & & & & & & $0,81 \mathrm{~ns}$ \\
F. (Cultivar) & & & & & & \\
F. (Local) & & & & & & \\
\hline
\end{tabular}

ns = não significativo. Médias seguidas por letras distintas diferem entre si pelo teste de Duncan a $5 \%$. 
O cultivar IAC 287 apresentou-se resistente ao agente causal da ferrugem-da-folha, comparado ao 'Anahuac', em condições de sequeiro, e ao 'IAC 24' nas áreas com irrigação.

A helmintosporiose causada pelo fungo Helminthosporium sativum sp. ou $H$. tritici repentis é de grande importância na triticultura, provocando epifitias severas e, consequientemente, reduções drásticas na produção de trigo.

Como demonstrado no quadro 9, a ocorrência da doença foi generalizada no Estado de São Paulo em 1987-91 para os cultivares IAC 72, IAC 227 e BH 1146, em condição de sequeiro, e também para os cultivares IAC 287 e Anahuac, em ambas as condições de cultivo, de acordo com o quadro 10 .

Todos os cultivares em estudo demonstraram suscetibilidade à doença, que se apresentou mais influenciada pelas condições climáticas de cada ano do que pelo local em estudo, independente da modalidade de cultivo.

As médias do comprimento de dez raízes dos cultivares IAC 72, IAC 227 e IAC 287, hem como dos controles BH 1146 e Anahuac, medidas após
72 horas de crescimento nas soluções nutritivas completas, que se seguiu a 48 horas de crescimento nas soluções de tratamento contendo seis diferentes concentrações de alumínio $(0,2,4,6,8$ e $10 \mathrm{mg} / \mathrm{li}$ tro) são representadas na figura 4 .

Todos os cultivares apresentaram redução no crescimento radicular nas soluções de tratamento contendo $\mathrm{Al}^{3+}$ em relação ao da solução de tratamento com $0 \mathrm{mg} /$ litro do elemento. Os cultivares Anahuac e IAC 287 revelaram-se muito sensíveis ao alumínio tóxico, pois suas raízes primárias não mostraram crescimento na solução com $2 \mathrm{mg} /$ litro de $\mathrm{Al}^{3+}$. O IAC 72 exibiu crescimento das raízes primárias até a concentração de $10 \mathrm{mg} /$ litro; entretanto, mostrou grande redução no crescimento a partir de $6 \mathrm{mg} /$ litro, podendo ser classificado como moderadamente sensível. O IAC 227 exibiu crescimento radicular até a concentração de $10 \mathrm{mg} / \mathrm{litro}$, o mesmo que seu genitor BH 1146, considerado tolerante.

A porcentagem média do crescimento das raízes dos cultivares de trigo medidas após doze dias de crescimento em soluções contendo diferentes concentrações de ferro, encontra-se na figura 5.

Quadro 8. Reações médias em porcentagem de área foliar infectada pelo agente causal da ferrugem-da-folha, nos cultivares de trigo IAC 287, Anahuac e IAC 24 em condições de sequeiro no período 1988-91 e com irrigação por aspersão no período 1987-91, nas localidades estudadas

\begin{tabular}{|c|c|c|c|c|c|c|c|c|c|c|c|}
\hline \multirow{2}{*}{ Cultivar } & \multicolumn{4}{|c|}{ Anos } & \multirow{2}{*}{ Média } & \multicolumn{5}{|c|}{ Anos } & \multirow{2}{*}{ Média } \\
\hline & 88 & 89 & 90 & 91 & & 87 & 88 & 89 & 90 & 91 & \\
\hline IAC 287 & 0 & 0 & 0 & 0 & 0 & 0 & 0 & 0 & 0 & 0 & $0,0 b$ \\
\hline Anahuac & 11,0 & 0 & 0 & 0 & 4,6 & 1,3 & 0 & 0 & 0 & 1,3 & $0,5 a b$ \\
\hline IAC 24 & - & - & - & - & - & 8,8 & 0 & 2,5 & 0 & 0 & $3,0 \mathrm{a}$ \\
\hline Média & 5,8 & 0 & 3,3 & 0 & - & 3,3 & 0 & 0,8 & 0 & 1,6 & - \\
\hline F. $(A n o)$ & & & & & $1,59 \mathrm{~ns}$ & & & & & & $1,42 \mathrm{~ns}$ \\
\hline F. (Cultivar) & & & & & $4,17 \mathrm{~ns}$ & & & & & & $3,15^{*}$ \\
\hline F. (Local) & & & & & $0,24 \mathrm{~ns}$ & & & & & & $2,06 \mathrm{~ns}$ \\
\hline
\end{tabular}

*: Significativo ao nível de 5\%; ns: não significativo. Médias seguidas por letras distintas diferem entre si pelo teste de Duncan a $5 \%$. 


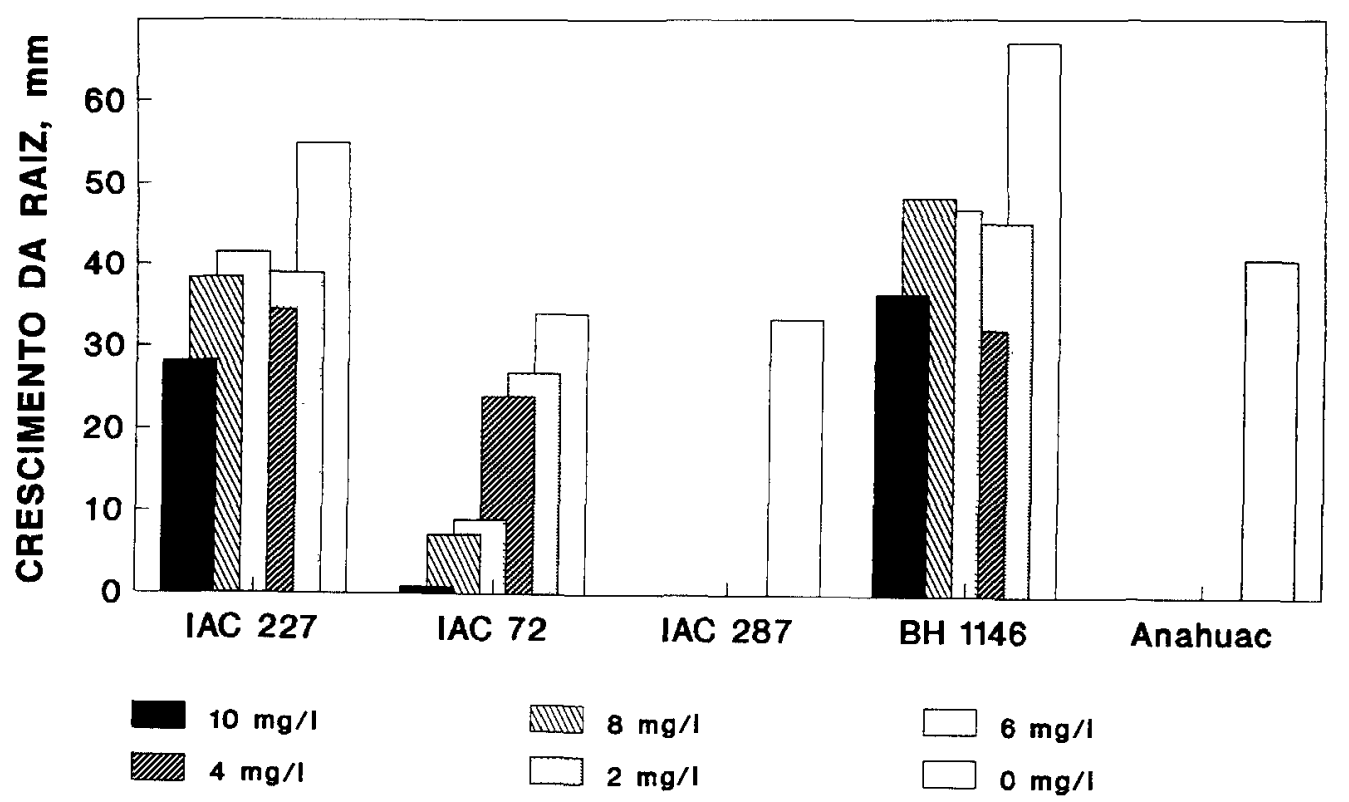

Figura 4. Comprimento médio, em milímetro, das raízes dos cultivares de trigo IAC 72, IAC 227 e IAC 287, e dos controles BH 1146 (tolerante) e Anahuac (sensível), medidos após 72 horas de crescimento em solução normal que se seguiu a crescimento em soluções contendo seis diferentes concentraçōes de alumínio.

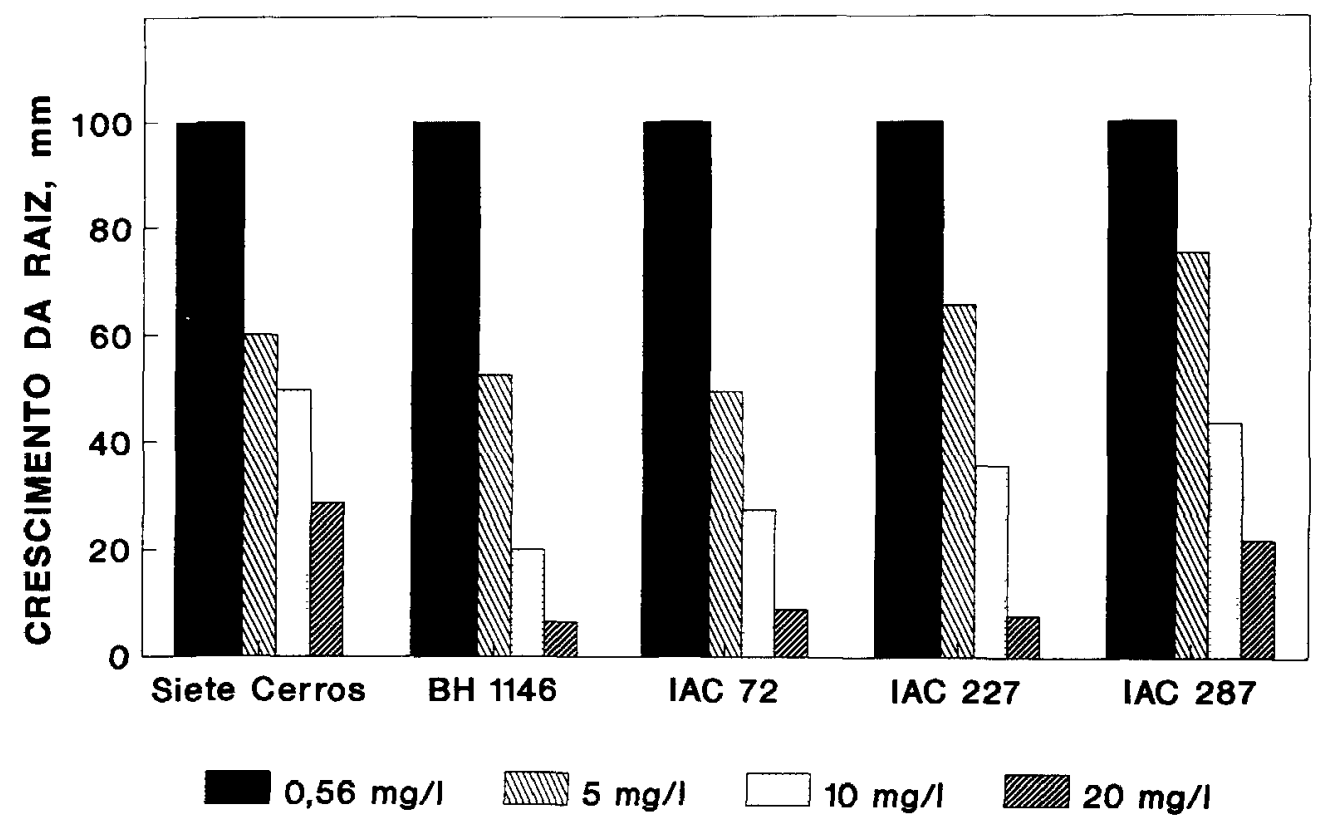

Figura 5. Porcentagem de crescimento das raízes dos cultivares de trigo IAC 72, IAC 227 e IAC 287, e dos controles Siete Cerros (tolerante) e BH 1146 (sensível), medidos após dez dias de crescimento em soluções contendo quatro diferentes concentrações de ferro. 
Os cultivares IAC 72 e IAC 227 apresentaram reduções no crescimento radicular causadas por altas doses de ferro; o mesmo ocorreu com o BH 1146, considerado sensível a esse elemento, de acordo com Camargo et al. (1988). O 'IAC 287' revelou a mesma tolerância do Siete Cerros. A suscetibilidade do 'IAC 227 ' provavelmente seja oriunda do 'BH 1146'. A elevada suscetibilidade do cultivar BH 1146 à toxicidade de manganês em doses elevadas está representada na figura 6, após doze dias de crescimento em soluções nutritivas contendo diferentes concentrações de manganês. O IAC 72 pode ser considerado como moderadamente sensível a esse elemento, porém os cultivares IAC 227 e IAC 287 revelaram-se tolerantes, em altas concentrações de manganês, um pouco superior à tolerância do Siete Cerros.

Quadro 9. Reações médias em porcentagem de área foliar infectada pelo agente causal de Helminthosporium sp., nos cultivares de trigo IAC 72 , IAC 227 e BH 1146 em condições de sequeiro no período 1987-91, nas localidades estudadas

\begin{tabular}{lllllll}
\hline Cultivar & 1987 & 1988 & 1989 & 1990 & 1991 & Média \\
\hline IAC 72 & 25,0 & 35,0 & 25,5 & 22,5 & 17,5 & $25,0 \mathrm{a}$ \\
IAC 227 & 25,0 & 37,5 & 20,0 & 22,5 & 15,0 & $25,0 \mathrm{a}$ \\
BH 1146 & 22,5 & 35,0 & 30,0 & 15,0 & 15,0 & $23,5 \mathrm{a}$ \\
Média & $24,2 \mathrm{~B}$ & $35,8 \mathrm{~A}$ & $25,0 \mathrm{~B}$ & $20,0 \mathrm{~B}$ & $15,8 \mathrm{~B}$ & - \\
F (Ano) & & & & & $4,95^{*}$ \\
F (Cultivar) & & & & & $0,08 \mathrm{~ns}$ \\
F (Local) & & & & $0,93 \mathrm{~ns}$ \\
\hline
\end{tabular}

*: Significativo ao nível de $5 \%$, ns: não significativo. Médias seguidas por letras distintas diferem entre si pelo teste dc Duncan a $5 \%$.

Quadro 10. Reações médias em porcentagem de área foliar infectada pelo agente causal de Helminthosporium sp., nos cultivares de trigo IAC 72, Anahuac e IAC 24 em condições de sequeiro no período 1988-91 e com irrigação por aspersão no período 1987-91, nas localidades estudadas

\begin{tabular}{|c|c|c|c|c|c|c|c|c|c|c|c|}
\hline Cultivar & 1988 & 1989 & 1990 & 1991 & Média & 1987 & 1988 & 1989 & 1990 & 1991 & Média \\
\hline & \multicolumn{5}{|c|}{ Sequeiro } & \multicolumn{6}{|c|}{ - Irrigado } \\
\hline IAC 287 & 20 & 43 & 16 & 16 & $24,2 \mathrm{a}$ & 20 & 6,3 & 32 & 20 & 25 & $20,8 \mathrm{a}$ \\
\hline Anahuac & 23 & 37 & 13 & 13 & $21,7 \mathrm{a}$ & 17 & 6,3 & 32 & 22 & 22 & $20,3 \mathrm{a}$ \\
\hline IAC 24 & - & - & - & - & - & 25 & 6,3 & 30 & 25 & 27 & $22,8 \mathrm{a}$ \\
\hline Média & $21 \mathrm{~B}$ & $40 \mathrm{~A}$ & $15 \mathrm{~B}$ & $15 B$ & - & $21 \mathrm{~B}$ & $6,3 \mathrm{C}$ & $32 \mathrm{~A}$ & $22 \mathrm{~B}$ & $25 \mathrm{AB}$ & - \\
\hline F (Ano) & & & & & $24,3 *$ & & & & & & $13,4^{*}$ \\
\hline F (Cultivar) & & & & & $1,08 \mathrm{~ns}$ & & & & & & $0,44 \mathrm{~ns}$ \\
\hline F (Local) & & & & & $2,98 \mathrm{~ns}$ & & & & & & $0,01 \mathrm{~ns}$ \\
\hline
\end{tabular}

\footnotetext{
*: Significativo ao nível de 5\%; ns: não significativo. Médias seguidas por letras distintas diferem entre si pelo teste de Duncan a 5\%.
} 


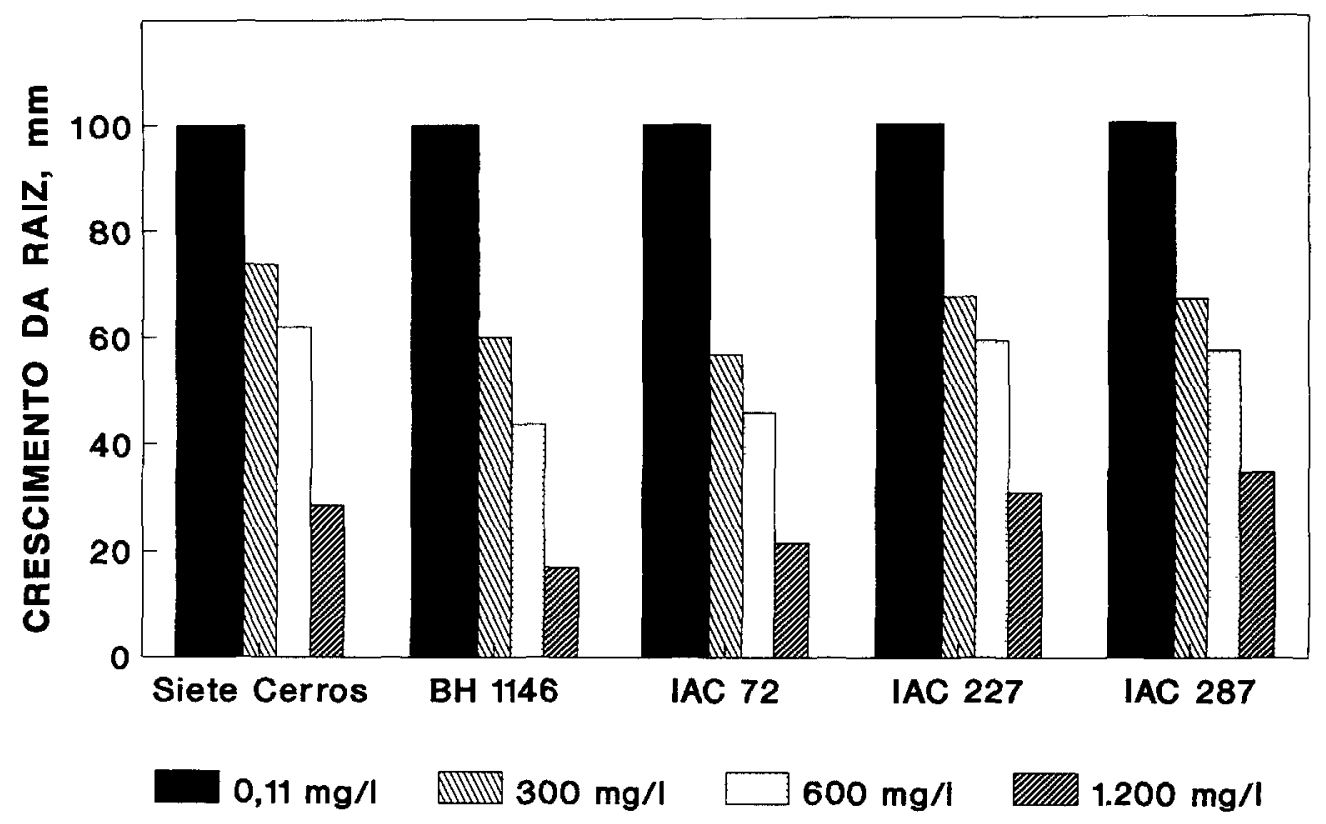

Figura 6. Porcentagem de crescimento das raízes dos cultivares de trigo IAC 72, IAC 227 e IAC 287, e dos controles Siete Cerros (tolerante) e BH 1146 (sensível), medidos após dez dias de crescimento em soluções contendo quatro diferentes concentrações de manganês.

A moagem dos grãos dos cultivares no Moinho Bühler propiciou rendimentos que variaram de 63,86 a $67,79 \%$, níveis esses superiores ao padrão (grão comercial). Convém salientar que, industrialmente, obtêm-se valores mais altos, devido ao maior número de quebras dos grãos, reduções e peneiras existentes nas unidades comparadas aos moinhos experimentais. No quadro 11 , os valores de porcentagem para farelos fino e grosso são considerados altos pelas razões expostas. Experimentalmente, os cultivares IAC 287 e IAC 72 foram superiores ao padrão. A maior porcentagem de farelo grosso do 'IAC 72' deve-se, provavelmente, ao fato de a amostra utilizada não ter sido passada por processo de beneficiamento. Quanto às perdas, o IAC 227 apresentou maior índice em relação às demais amostras.

No quadro 12, está expresso o teor de glúten úmido dos cultivares e a atividade enzimática das farinhas medidas em segundos pelo "falling num- ber". A amostra IAC 287 destacou-se das demais pelo elevado conteúdo em glúten úmido $(40,9 \%)$, e os cultivares IAC 227 e IAC 72 apresentaram 34,4 e $33,8 \%$ respectivamente, um pouco superiores ao da farinha comercial $(31,2 \%)$. No "falling number", a amostra comercial mostrou uma atividade enzimática maior que as demais amostras, mas den-

Quadro 11. Características de moagem dos cultivares IAC 72, IAC 227 e IAC 287 e do padrão comercial

\begin{tabular}{lcccc}
\hline Amostra & $\begin{array}{c}\text { Rendimento } \\
\text { em farinha }\end{array}$ & $\begin{array}{c}\text { Farelo } \\
\text { grosso }\end{array}$ & $\begin{array}{c}\text { Farelo } \\
\text { fino }\end{array}$ & Perdas \\
\hline & & & & \\
IAC 72 & 67,79 & 25,60 & 15,60 & 1,01 \\
IAC 227 & 63,86 & 17,64 & 13,08 & 5,42 \\
IAC 287 & 66,10 & 17,79 & 12,71 & 3,04 \\
Comercial & 65,21 & 17,73 & 16,52 & 0,54 \\
\hline
\end{tabular}


Quadro 12. Teores de glúten e "falling number" dos cultivares de trigo IAC 72, IAC 227, IAC 287 e do padrão comercial. Média de três repetições

\begin{tabular}{lcc}
\hline Amostra & $\begin{array}{c}\text { Teor de glúten } \\
\text { úmido }\end{array}$ & $\begin{array}{c}\text { "Falling } \\
\text { number" }\end{array}$ \\
\hline IAC 72 & seg \\
IAC 227 & 38,8 & 392 \\
IAC 287 & 34,4 & 414 \\
Comercial & 40,9 & 443 \\
\hline
\end{tabular}

tro dos limites usuais (em se tratando de grãos comerciais, provavelmente seja uma mistura de cultivares em proporções desiguais). Em relação às demais amostras, deve-se salientar a necessidade de uma pequena adição de enzimas para se abaixar um pouco os valores e trazê-los para aproximadamente 300 segundos, que seria ideal. Com o uso de unificados que já contêm as enzimas alfa-amilase, consegue-se essa aproximação.

Os resultados do farinógrafo - Quadro 13 revelaram uma tendência a dar melhores valores de volume específico na panificação para a amostra IAC 287, não só pela melhor estabilidade da massa ( $\mathrm{E}=3$ minutos), mas, também, pelo baixo valor de abrandamento, índice que representa a manutenção das características reológicas da massa. As outras amostras revelaram valores de esta- bilidade idêntica. $O$ cultivar IAC 72 foi o que se mostrou menos estável em relação ao abrandamento (Abr. = 200 U.B.).

No quadro 14 estão expressos os resultados (parâmetros) do expansograma e do extensograma das massas provenientes da farinha dos cultivares. No expansógrafo, o IAC 287 apresentou índice de produção (P.G. $=92 \mathrm{~mm}$ ) e de retenção de gás $(\mathrm{E} .=74 \mathrm{~mm})$ mais próximos ao ideal. Indica melhores condições de panifficação, pois o $\mathrm{CO}_{2}$ deve ser produzido em quantidades boas para fazer a massa crescer e, esse mesmo gás, deve ser mantido preso para evitar seu desperdício. Com relação à extensibilidade da massa, as amostras do IAC 287 e IAC 227 se mostraram mais extensíveis. Esses cultivares foram os que melhores resultados propiciaram com respeito à área $\left(\mathrm{cm}^{2}\right)$.

Ainda em relação a algumas características reológicas das massas obtidas das farinhas - Quadro 15 - praticamente confirmam os resultados das atividades enzimáticas - "falling number" - obtidos no quadro 12. A amostra do IAC 287 revelou o mais alto valor de viscosidade, indicando menos atividade diastática da farinha, da mesma forma que, nos resultados de "falling number", a amostra padrão apresentou uma atividade diastática maior.

Entretanto, de nenhum dos métodos reológicos ou químicos empregados isoladamente, é possível prever exatamente as características finais do produto. Esses critérios são apenas indicativos.

Quadro 13. Características farinográficas das farinhas dos cultivares IAC 72, IAC 227, IAC 287 e do padrão comercial

\begin{tabular}{lccccc}
\hline Amostra & $\begin{array}{c}\text { Absorção } \\
\text { de água }\end{array}$ & $\begin{array}{c}\text { Tempo de } \\
\text { desenvolvimento }\end{array}$ & Resistência & Estabilidade & Abrandamento \\
\cline { 3 - 5 } & $\%$ & & min & U.B. $\left({ }^{1}\right)$ \\
IAC 72 & 63,2 & 2,0 & 2,5 & 0,5 & 200 \\
IAC 227 & 64,6 & 3,5 & 4,0 & 0,5 & 140 \\
IAC 287 & 58,9 & 2,5 & 5,5 & 3,0 & 80 \\
Comercial & 61,0 & 3,0 & 3,0 & 0,5 & 80 \\
\hline
\end{tabular}

( ${ }^{1}$ ) Unidade de Brabender. 


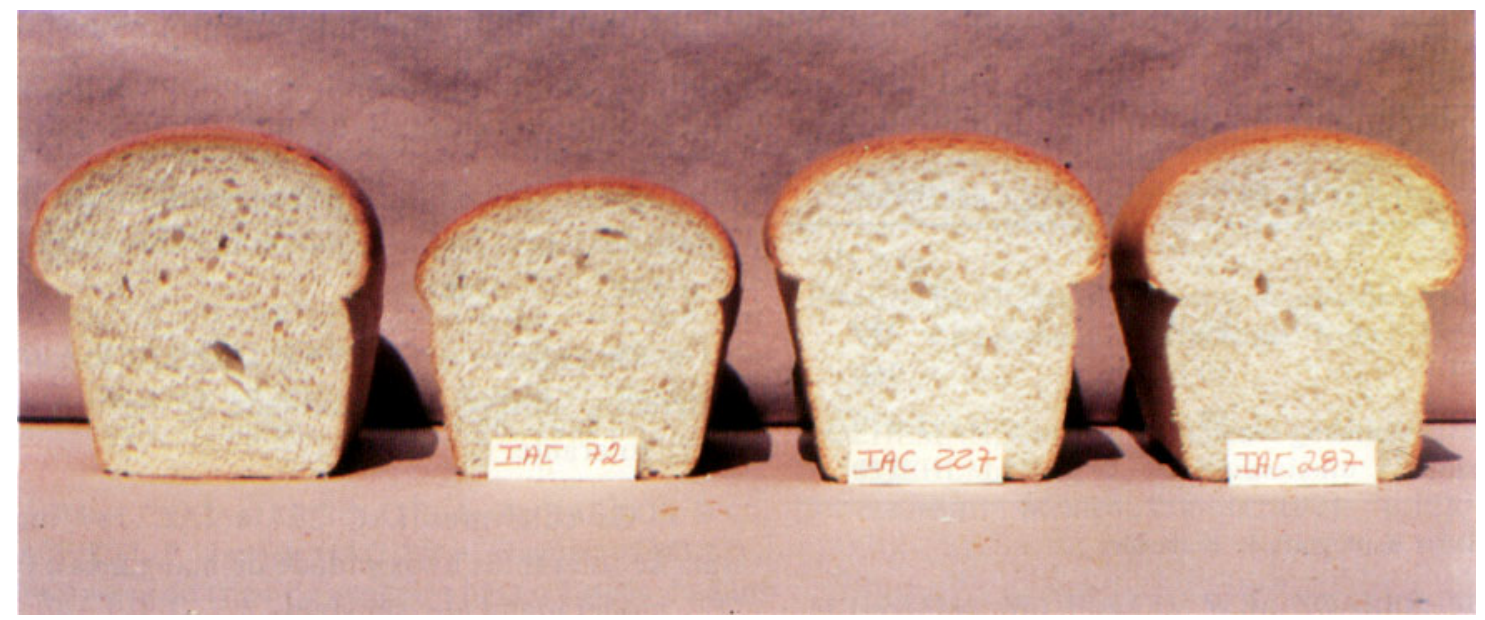

Figura 7. Volume específico comparativo dos pães obtidos com a farinha dos cultivares IAC $72(83,4 \%)$, IAC $227(103,76 \%)$ e IAC $287(105,64 \%)$ em relação à farinha comercial $(100 \%)$.

Quadro 14. Características expansográficas e extensográficas da farinha dos cultivares IAC 72, IAC 227, IAC 287 e do padrão comercial

\begin{tabular}{lccccccc}
\hline \multirow{2}{*}{ Amostra } & \multicolumn{2}{c}{ Extensógrafo } & & \multicolumn{2}{c}{ Expansógrafo } \\
\cline { 2 - 3 } & Resistência( $\left.{ }^{1}\right)$ & $\begin{array}{c}\text { Exten- } \\
\text { sibilidade }\end{array}$ & Razão & Área & & $\begin{array}{c}\text { Produção } \\
\text { de gás }\end{array}$ & Estabilidade \\
\hline IAC 72 & U.E. & $\mathrm{mm}$ & & $\mathrm{cm}^{2}$ & & \\
IAC 227 & 590 & 127 & 2,64 & 107 & & 82 & 73 \\
IAC 287 & 230 & 190 & 1,21 & 233 & & 61 & 43 \\
Comercial & 520 & 160 & 3,25 & 151 & & 92 & 74 \\
\hline
\end{tabular}

( ${ }^{1}$ Resistência em unidades extensográficas Brabender.

No quadro 16, têm-se os resultados do teste de panificação em termos de volume específico comparativo (VEC), que expressa a leveza do pão, e a avaliação final comparativa ( $\mathrm{AFC}$ ), que considera, além da leveza, aspectos como a cor (interno e externo), simetria e textura, ambas em relação ao padrão.

Avaliando os dados médios quanto ao potencial de panificação, a amostra IAC 287 foi superior à comercial em $5,64 \%$ e a melhor entre as estudadas. O 'IAC 227 ' apresentou volume específico comparativo de $3,76 \%$ superior ao padrão; entretanto, na avaliação final comparativa, esteve inferior ao padrão, em vista de a cor externa ser um pouco mais escura e a crosta ligeiramente mais grossa comparada a este e ao IAC 287 (Figura 7). O 'IAC 72' apresentou menor volume e características interna e externa inferiores aos demais. 
Quadro 15. Características amilográficas da farinha dos cultivares IAC 72 , IAC 227 , IAC 287 e do padrão comercial

\begin{tabular}{lcc}
\hline Amostra & $\begin{array}{c}\text { Temperatura inicial } \\
\text { de gelatinização }\end{array}$ & $\begin{array}{c}\text { Viscosidade } \\
\text { máxima }\end{array}$ \\
\hline & ${ }^{\circ} \mathrm{C}$ & U.A. $\left({ }^{\mathbf{l}}\right)$ \\
IAC 72 & 68,0 & 540 \\
IAC 227 & 59,0 & 960 \\
IAC 287 & 59,0 & 1.170 \\
Comercial & 58,5 & 320 \\
\hline
\end{tabular}

(1) Unidades amilográficas Brabender.

Quadro 16. Características dos pães obtidos com as farinhas dos cultivares IAC 72, IAC 227, IAC 287 e do padrão comercial

\begin{tabular}{|c|c|c|}
\hline Amostra & $\begin{array}{l}\text { Volume } \\
\text { específico }\end{array}$ & $\begin{array}{l}\text { Avaliação } \\
\text { final }\left(^{2}\right)\end{array}$ \\
\hline
\end{tabular}

\begin{tabular}{lrr} 
IAC 72 & 83,40 & 99,10 \\
IAC 227 & 103,76 & 99,66 \\
IAC 287 & 105,64 & 100,00 \\
Comercial & 100,00 & 100,00 \\
\hline
\end{tabular}

(1) Comparativo à farinha de trigo comercial (VEC $=100$ ).

$\left.{ }^{2}\right)$ Comparativa à farinha de trigo comercial $(\mathrm{AFC}=100$ ).

\section{CONCLUSÕES}

1. O cultivar IAC 227 apresentou diferença significativa na produtividade de grãos, em comparação ao IAC 72 e à testemunha $\mathrm{BH} 1146 \mathrm{em}$ condições de sequeiro.

2. O ' 287 ' foi superior em $10 \%$ na média da produtividade de grãos, ao cv. Anahuac, no Vale do Paranapanema, e em 7 e $6 \%$ aos controles Anahuac e IAC 24 respectivamente, em áreas com irrigação.

3. O IAC 287 apresentou reação de resistência às raças das ferrugens-do-colmo e da-folha, testadas em casa de vegetação e em condições de campo, sendo os demais cultivares suscetíveis.

4. Todos os cultivares se apresentaram suscetíveis ao agente causal da helmintosporiose.

5. O IAC 287 demonstrou suscetibilidade ao alumínio tóxico; o IAC 72, moderada suscetibilidade, e o IAC 227, tolerância.

6. Os cultivares IAC 72 e IAC 227 foram considerados sensíveis à toxicidade do ferro e o IAC 287 , tolerante.

7. Os cultivares IAC 227 e IAC 287 mostraram-se tolerantes à toxicidade de manganês e o IAC 72, moderadamente sensível.

8. No teste de panificação, O 'IAC 287' apresentou-se com melhor volume específico comparativo que os demais cultivares analisados também quanto à farinha comercial.

\section{REFERÊNCIAS BIBLIOGRÁFICAS}

ALLARD, R.W. Principles of plant breeding. New York, John Wiley, 1960. $181 \mathrm{p}$.

AMERICAN ASSOCIATION OF CEREAL CHEMISTS (AACC). Methods of analysis of AACC. St. Paul, Minnesota, 1969.

ARBEITSGEMEINSCHALT fuer Getreidefosghung Standart fuer Gertreide und, Brot. Detmold, Moritz Schaefer, 1971. 138p.

$\mathrm{BÄR}$, W.H. Análise e avaliação do trigo e dos produtos derivados. Campinas, ITAL, 1982. 154p.

CAMARGO, C.E. de O. Estudos de variedades de trigo para o Estado de São Paulo. Piracicaba, 1972. 102p. Tese (Doutorado) - ESALQ-USP, 1972.

CAMARGO, C.E. de O.; FELÍ́CIO, J.C.; FREITAS, J.G. \& FERREIRA FILHO, A.W.P. Tolerância de trigo, triticale e centeio a diferentes níveis de ferro em solução nutritiva. Bragantia, Campinas, 47(2):295304, 1988.

CAMARGO, C.E. de O.; FELÍCIO, J.C. \& ROCHA JUNIOR, L.S. Trigo: tolerância ao alumínio em solução nutritiva. Bragantia, Campinas, 46(2):183-190, 1987. 
CAMARGO, C.E. de O. \& OLIVEIRA, O.F. Tolerância de cultivares a diferentes níveis de manganês em solução nutritiva. Bragantia, Campinas, 42:65-78, 1983.

CUYABANO, N. A cultura do trigo. Campinas, Divisão de Assistência Especializada, 1964, 23p. (Instruções técnicas, 9)

FELÍCIO, J.C.; BARROS, B.C.; CAMARGO, C.E. de O. \& BÄR, W.H. Maracaí (IAC 17) e Xavantes (IAC 18): cultivares de trigo para o Estado de São Paulo. Bragantia, Campinas, 42(1):15-25, 1983.

FELÍCIO, J.C.; CAMARGO, C.E. de O.; BARROS, B.C \& VITTI, P. Iguaçu (IAC 21) e Araguaia (IAC 22): cultivares de trigo-de-sequeiro para o Estado de São Paulo. Bragantia, Campinas, 44(1):115-128, 1985.

FELICÍO, J.C.; CAMARGO, C.E.O.; FERREIRA FILHO, A.W.P. \& CASTRO, J.L. Comportamento de cultivares de triticale no Estado de São Paulo no período de 1985 a 1987. Pesquisa Agropecuária Brasileira, Brasília, 25(8):1143-1149, 1990a.

FELÍCIO, J.C.; CAMARGO, C.E. de O; FERREIRA FILHO, A.W.P.; FREITAS, J.G.; BARROS, B.C. \& VITTI, P. Tocantins (IAC 23) e Tucuruí (IAC 24): novos cultivares de trigo. Bragantia, Campinas, 47(1):93-107, 1988.

FELÍCIO, J.C.; CAMARGO, C.E. de O.; FERREIRA FILHO, A.W.P.; VITTI, P. \& GALLO, P.B. IAC 25 'Pedrinhas' e IAC 161 'Taiamã': novos cultivares de trigo. Bragantia, Campinas, 49(1):105-125, $1990 \mathrm{~b}$.

FELICÍO, J.C.; CAMARGO, C.E.O.; PIZZINATTO, A.; CASTRO, J.L. \& GALLO, P.B. Comportamento agronômico e avaliação tecnológica de genótipos de triticale no Estado de São Paulo em 1988 a 1989. Pesquisa Agropecuária Brasileira, Brasília, 28(3):281-294, 1993.

HANSON, H.; BORLAUG, N.E. \& ANDERSON, R.G. Trigo en el tercer mundo. México, Centro Internacional de Mejoramiento de Maiz y Trigo, 1982. 166p.
MUNDSTOCK, C.M. Cultivo de cereais de estação fria: trigo, aveia, centeio, alpiste e triticale. Porto Alegre, Gráfica Editora NBS, 1983. 265p.

OSÓRIO, E.A. Variedades e melhoramento. In: OSÓRIO, E.A., coord. Trigo no Brasil. Campinas, Fundação Cargill, 1982. v.1, p.147-197.

PIMENTEL GOMES, F. Curso de estatistica experimental. 4.ed.rev.ampl. Piracicaba, Nobel, 1970. 430p.

POEHLMAN, J.M. Mejoramiento genético del trigo. In: POEHLMAN, J.M. Mejoramiento genético de las cosechas. México, Limusa, 1974. p.123-150.

SCHRAMM, W.; FULCO, W.S.; SOARES, M.H.G. \& ALMEIDA, A.M.P. Resistência de cultivares de trigo em experimentação ou cultivo no Rio Grande do Sul: às principais doenças fúngicas. Agronomia Sulriograndense, Porto Alegre, 10(1):31-39, 1974.

SILVA, E.M.; LUCHIARI JUNIOR, A.; GUERRA, A.F. \& GOMIDE, R.L. Recomendação sobre o manejo de irrigação em trigo para a região dos cerrados. In: REUNIÃO DA COMISSÃO NORTE-BRASILEIRA DE PESQUISA DE TRIGO, 10., Campinas, 1984. Ata. Brasília, EMBRAPA-CPAC, 1984. 60p.

SILVA, J.R.; LINS, R.E. \& JUNQUEIRA, R.C. Informes sobre a comercialização do trigo. Informaçóes Econômicas, São Paulo, 19:157, 1989. (Suplemento, 01/89)

TEIXEIRA, E.F. O trigo no Sul do Brasil. São Paulo, Linotype, 1958. 300p.

VITTI, P.; LEITÃO, R.F.F.; PIZZINATTO, A. \& PENTEADO, R.L.B. Preparo de uma farinha de milho integral desengordurada e seu uso em panificação. Boletim do ITAL, Campinas, 17(4):451-467, 1980.

VITTI, P.; MOREIRA, R.T. \& BÄR, W.R. Estudo tecnológico do cultivar de trigo nacional IAC 18 . Boletim do ITAL. Campinas, 19(2):183-194, 1982. 